Ann. Biol. anim. Bioch. Biophys., I965, 5 (2), I63-187.

\title{
ÉTUDE BIOCHIMIQUE DE LA CROISSANCE DE L'INTESTIN GRELLE, DU FOIE ET DE LA CARCASSE DU RAT; RÔLES RESPECTIFS DE LA MULTIPLICATION ET DU GRANDISSEMENT CELLULAIRES.
}

\author{
G. DURAND, G. FAUCONNEAU et Éliane PENOT \\ avec la collaboration technique de Noëlle Borrgeacx \\ Laboratoire d'Étude des Métabolismes \\ Centre national de Recherches zootechniques, Jouy-en-Josas (Seine-et-Oise)
}

\section{SOMMAIRE}

La recherche de tests biochimiques permettant l'étude de l'évolution de phénomènes liés à la croissance de tissus et organes animaux a été entreprise.

Cette recherche est fondée sur la mesure :

$I^{0}$ des variations de la teneur en acide désoxyribonucléique (ADN) dont la quantité est proportionnelle au nombre de noyaux. En divisant le poids d'un organe ou d'un tissu par l'ADN qu'il contient, on obtient une valeur moyenne, proportionnelle à la quantité de matière vivante associée à chaque noyau. Par convention, l'ensemble d'un noyau et de la quantité moyenne de matière vivante qui lui est associée est appelée "Cellule ". Cette convention étant admise, le rapport Poids frais

ADN est proportionnel au poids des "cellules", qui varie avec la taille des "cellules";

$2^{0}$ de l'évolution de certains aspects de l'activité cellulaire, mesurée par les teneurs en acide ribonucléique (ARN) et en nucléotides acido-solubles.

En outre, une relation mathématique permettant d'apprécier l'influence relative sur la croissance de l'augmentation du nombre de cellules et du grandissement moyen de celles-ci, a été établie. La méthode a été appliquée aux intestins grêles, aux foies et aux "carcasses " de rats mâles en croissance (3 à 17 semaines). Elle a permis de montrer que :

la croissance de l'intestin grêle s'achève précocement et qu'elle est due d'abord principalement, puis exclusivement à l'augmentation du nombre de cellules ;

la croissance du foie dure pendant toute la période étudiée. La multiplication cellulaire est toujours le facteur principal de cette croissance bien qu'au-delà de 7,5 semaines l'influence du grandissement cellulaire devienne de plus en plus importante ;

la croissance de la carcasse devient moins rapide à partir de Io semaines. L'augmentation du nombre de cellules est facteur princjpal de la croissance jusqu'à 7 semaines ; ensuite le grandissement cellulaire l'emporte. L'analyse globale (eau, lipides, protéines, cendres) a été effectuée. 


\section{INTRODUC'TION}

La croissance d'un animal se traduit de la façon la plus apparente par une augmentation de poids vif du corps entier. Ia méthode la plus simple et la plus couramment utilisée pour l'apprécier est donc de mesurer le gain de poids vif en fonction du temps. Elle a permis à BRODx (I945), (en rassemblant des résultats obtenus par de nombreux auteurs) d'établir certaines lois mathématiques qui gouvernent la croissance. La méthode ne fournit cependant que des résultats globaux, qui ne tiennent pas compte des particularités des divers organes et tissus dont l'animal est constitué ; en outre, elle n'apprend rien sur les phénomènes biologiques et biochimiques dont la croissance est le résultat. Aussi a-t-elle été souvent complétée par d'autres méthodes:

dissection,

composition chimique du corps entier, d'organes ou de tissus, évolution de la teneur en certains composés, examens histologiques, etc.

Le travail qui suit est une contribution à la recherche de tests biochimiques qui permettent de suivre d'une façon précise la croissance d'organes et de tissus animaux.

Les recherches de ces tests sont fondées sur l'étude:

$A$, de la composition chimique élémentaire des organes et tissus,

$B$, de la division et du grandissement cellulaires,

C, de certains aspects de l'activité cellulaire.

\section{A. Composition chimique élémentaire des tissus}

La variation des teneurs relatives des tissus et organes en protéines $(N \times 6,25)$, eau, minéraux et lipides au cours de la croissance est un fait bien connu, étudié par de nombreux auteurs.

\section{B. Division et grandissement cellulaires}

NeEdham (I933) définissait la croissance comme étant la résultante " de la multiplication cellulaire, de l'augmentation de la taille des cellules, de l'augmentation de la quantité de matière structurale non vivante".

Autrement dit : la croissance met en jeu la multiplication cellulaire, le grandissement cellulaire et l'augmentation des tissus interstitiels.

En adoptant ce principe, on peut écrire, qu'à un instant donné :

$$
\mathrm{P}=\mathrm{N}_{1} \times p_{1}+\mathrm{I}
$$

$P$ étant le poids d'un tissu, d'un ensemble de tissus, d'un organe ou d'un animal entier

$\mathrm{N}_{1}$, le nombre de cellules,

$p_{1}$, le poids moyen de chaque cellule,

$I$, le poids des tissus interstitiels.

Cette relation serait satisfaisante, s'il était vrai que l'animal fût vraiment constitué d'un édifice de cellules bien isolées et idéales, chacune possédant un noyau, un cytoplasme et une membrane cytoplasmique. 
Or, il se trouve que certains tissus ne sont pas organisés de la sorte : le tissu musculaire est constitué de fibres plurinucléées; une proportion importante des cellules du foie et du pancréas sont binucléées, etc. D'autre part, $p_{1}$ est essentiellement variable suivant les tissus : il doit être considéré seulement comme une valeur moyenne. Quant au matériel interstitiel, il est soumis à des fluctuations si nombreuses et incessantes, et se trouve en rapport tellement étroit avec le milieu dit " cellulaire " qu'il paraît difficile à individualiser.

Puisque, de toute façon, on en est réduit à utiliser des valeurs moyennes, à la relation (I), sera préférée la relation (2) :

$$
\mathbf{P}=\mathrm{N} \times p
$$

ou $\mathrm{P}$ est le poids (g) d'un organe ou d'un tissu (ou d'un ensemble de tissus),

$\mathrm{N}$, le nombre de noyaux,

$p$, la quantité moyenne (en poids) de matière vivante associée à chaque noyau.

Par convention, on appellera " cellule " 1'ensemble d'un noyau et de la quantité movenne de matière vivante qui lui est associée. Le nombre de "cellules " est donc égal au nombre de noyaux et le rapport $\frac{\text { Poids frais (d'un tissu ou d'un organe) }}{\text { Nombre de noyaux }}$ permet d'apprécier la " taille des cellules".

Ces conventions étant admises, le premier problème qui se pose est l'étude de la multiplication " cellulaire ". Il a pu être résolu par la mise en ouvre de la découverte de Borvin et VENDRELY (I948) confirmée par de très nombreux auteurs (Mrrsky et Ris, I95I ; DAvidson et LEsLiE, I950 ; Thomson et al., I953), à savoir que la quantité moyenne d'acide désoxyribonucléique (ADN) contenu dans un noyau diploïde, pour une espèce donnée, est constante. Le nombre de noyaux (et donc de "cellules ») d'un organe ou d'un tissu est donc proportionnel à la quantité d'ADN qu'il contient, et a posteriori, toute variation de l'ADN correspond à une variation proportionnelle du nombre de cellules.

Ayant déterminé la quantité d'ADN, le rapport poids frais (d'un organe ou d'un tissu)/ADN nous fournit d'après la relation (2) la " taille des cellules".

Il est possible avec une telle méthode (déjà utilisée par EiNEsco et LEBI.oND, I962) de suivre l'évolution et du nombre de cellules et de leur taille au cours de la croissance.

\section{Activité cellulaire}

a) $A R N$ et protéines.

La synthèse des protéines est un facteur primordial de la croissance. Or, elle est liée, comme de très nombreux travaux l'ont montré (CASPERSSON, I950; BRACHET, I950, I954, I955; ALLFREY et al., I954) à l'acide ribonucléique (ARN). I1 est donc de tout premier intérêt de suivre l'évolution de 1'ARN et des protéines à l'intérieur de la cellule.

b) Nucléotides acido-solubles.

Les nucléotides acido-solubles sont connus comme étant des précurseurs des acides nucléiques (HURLBERT, I952-I954; FiD MONDS et LEPAGE, I953), des coenzymes et des transporteurs d'énergie. Il a paru intéressant de suivre leur évolution au cours de la croissance. 


\section{Organes et tissus choisis.}

Ce travail concerne l'intestin grêle (sans séreuse), le foie et la " carcasse " du rat. Nous entendons par " carcasse " l'ensemble du corps de l'animal moins le foie, l'intestin grêle et le gros intestin (ce dernier est écarté et n'est soumis à aucune analyse).

\section{MATÉRIEL ANIMAL}

Cinq lots de 15 rats mâles (Wistar) ont été utilisés; seuls étaient abattus les animaux dont le poids vif ne s'écartait pas de plus de 5 ou 6 p. Ioo de la moyenne du lot entier.

TABLEAU I

\begin{tabular}{|c|c|c|c|c|c|}
\hline Numéro du lot & 1 & 2 & 3 & 4 & 5 \\
\hline $\begin{array}{l}\text { Age (semaines) } \ldots \ldots \ldots \ldots \ldots \\
\text { Poids }(\mathrm{g}) \ldots \ldots \ldots \ldots \ldots \ldots \\
\text { Nombre de rats abattus . }\end{array}$ & $39 \stackrel{3}{ \pm} \underset{15}{ \pm} 2$ & $106 \underset{10}{5}$ & $193 \stackrel{7,5}{ \pm}$ & $282 \stackrel{10}{ \pm}$ & $393 \stackrel{17}{\div} \div 25$ \\
\hline
\end{tabular}

Alimentation des animaux

\section{Lot 1 .}

Les animaux sacrifiés le jour de sevrage, n'ont théoriquement consommé que le lait maternel. En fait, il est probable qu'au cours des 4 ou 5 derniers jours, ils aient consommé quelque peu de la nourriture apportée aux mères.

Lots $2-3-4-5$.

Après sevrage, les animaux ont reçu pendant une semaine un aliment équilibré à base de blé et de farine de poisson (I8 p. Ioo de matières azotées). Cette semaine d'adaptation permet d'éliminer les animaux dont la vitesse de croissance pondérale s'écarte déjà trop de la moyenne. Les lots sont alors constitués de rats âgés de 28 jours (pesant $65^{-7}$ o g) et on leur distribue ad libitum comme aliment, le mélange semi-synthétique ( 16 p. Ioo de matières azotées) dont la composition centésimale est indiquée en g dans le tableau 2.

TABLEAU 2

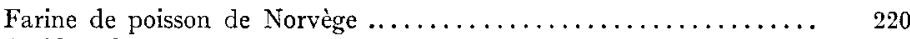

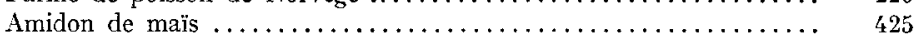

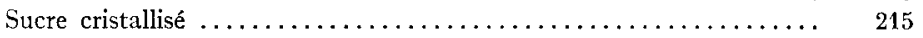

Intule d'arachide (brute de pression) + vitamines $\mathrm{A}$ et $\mathrm{D} \ldots \ldots \ldots . \quad 80$

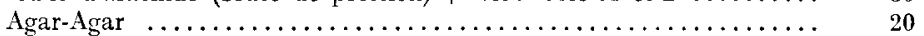

Mélange minéral (Osborne et. Mended) ................. 30

Mélange vitaminique (Henry et Rérat, 1963) $\ldots \ldots \ldots \ldots \ldots \ldots \ldots .10$

A I $000 \mathrm{~g}$ du mélange sont ajoutés $500 \mathrm{ml}$ d'eau de façon à obtenir une pâte fluide. L'aliment ainsi composé est distribué ad libitum; un tel régime permet un gain de poids moyen quotidien voisin de $5,3 \mathrm{~g}$ entre la $4^{\mathrm{e}}$ et la $10^{\mathrm{e}}$ semaine. 


\section{Abattage et prélè̃énent}

Chaque animal est anesthésié à l'éther; après incision abdominale, on injecte à l'aide d'une seringue dans la lumière de l'intestin grêle, aussi près que possible du pylore, io à $15 \mathrm{ml}$ d'acide trichloracétique (ATC) à Io p. roo. Toutes les réactions enzymatiques de l'organe étant ainsi bloquées, on le ligature à ses deux extrémités. Le foie est alors prélevé. puis l'intestin grêle (ce dernier sans sa séreuse, qui se détache du reste de l'organe après l'injection d'ATC). Tous les deux sont rincés au sérum physiologique à $0^{\circ} \mathrm{C}$ et plongés immédiatement dans l'azote liquide. Le gros intestin (cæcum + rectum) est éliminé. Il reste ce que nous avons défini plus haut comme étant " la carcasse ". Celle-ci est pesée, immergée deux minutes dans l'azote liquide, pour produire une congélation rapide des tissus, puis stockée $\grave{a}-18^{\circ} \mathrm{C}$.

\section{MÉTHODES CHIMIQUES}

\section{I. - TRAITEMENTS DU FOIE ET DE L'INTESTIN GRÊLE}

\section{Extraction et séparation des nucleotides acido-solubles.}

Immédiatement après l'abattage, les foies et les intestins grêles réunis, sont retirés de l'azote liquide et pesés. Yous obtenons ainsi le poids frais moven de chaque organe. On procède alors à l'extraction et à la séparation des nucléotides acido-solubles suivant une méthode inspirée de celle de Hurlbert et al. (1954).

\section{a) Extraction.}

Des fractions de $25 \mathrm{~g}$ environ sont réparties dans des pots de mixeurs (Blendor et Turmix) contenant $150 \mathrm{ml}$ d'A $\mathrm{A}^{\mathrm{T} C} \mathrm{a}$ à $10 \mathrm{p}$. Ioo maintenus à $0^{\circ},-2^{\circ} \mathrm{C}$.

On effectue trois broyages successifs de $\mathrm{I} / 2$ minute à $\mathrm{I} 4000 \mathrm{t} / \mathrm{m}$. Les brovats sont centrifugés pendant ro minutes à I $800 \mathrm{~g}$ (dans une centrifugeuse Jouan $\mathrm{G} 57 \mathrm{R}$ ) refroidie à $\mathrm{O}^{\circ},-2^{\circ} \mathrm{C}$. Le surnageant est filtré. On répète 3 fois cette opération. Les filtrats sont réunis et on en extrait la plus grande partie de l'ATC par 4 extractions successives à l'éther sulfurique refroidi (V/V). Il reste environ 3 à 5 méq. d'ATC pour I $000 \mathrm{ml}$ d'extrait et le $\mathrm{pH}$ est de $3,5-4$. HurlberT et al. (I954) utilisent l'acide perchlorique. Mais il est impossible d'éliminer complètement celui-ci en le précipitant sous forme de $\mathrm{ClO}_{4} \mathrm{~K}$ et il reste, à la température ou nous opérons, 70 - Ioo méq. d'acide perchlorique, pour I $000 \mathrm{ml}$ d'extraits; en outre, cet acide provorue des destructions de certains nucléotides "sucres " (Denayur R., Fauconneau G., non publié).

\section{b) Fractionnement et dosage.}

L'extrait obtenu après élimination de l'ATC est soumis à un fractionnement par chromatographie sur colonne de résine Dowex I $\times 8$ (200-400 mesh) sous forme IICOO-.

Quelques précisions concernant les modalités du fractionnement sont portées sous la figure I.

Un collecteur automatique recueille l'éluat par fractions de $18 \mathrm{ml}$. Les densités optiques d'une fraction sur trois sont mesurées au spectrophotomètre Jobin et Y'von à $260-275-290$ et 3 Io mu pour situer les pics.

Les fractions constituant chaque pic sont mélangées, amenées à un volume déterminé. Les densités optiques des mélanges ainsi obtenus sont mesurées au spectrophotomètre et aux longueurs

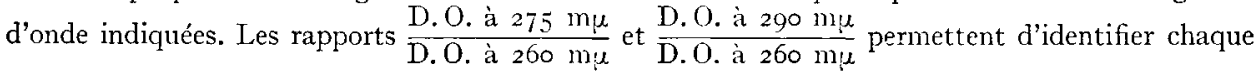
nucléotide et aussi de juger de la qualité de la séparation. Si le composé s'avère pur, les coefficients d'extinction molaire, bien définis pour les $\mathrm{pH}$ correspondant aux produits d'élution utilisés (système $\mathrm{pH}$ 2) (1) permettent de calculer la quantité de chaque nucléotide (exprimée en $\mu$ moles).

(1) Coefficients d'extinction molaire utilisés à pH 2 et $260 \mathrm{~m} \mu$ : nuléotides de l'adénine : 14,6 - de l'uracyle : $9,9-$ de la cytosine : 7,0 - de la guanine : $11,6-$ du DPN : 18,0 . 
Cette méthode chromatographique permet de recouvrer aprés èlution $9^{8} \mathrm{p}$. 100 de ce qui a été fixé sur la colonne de résine.

La fidélité est de 3 p. Ioo environ pour des composés dont la quantité fixée atteint au moins I mu. Les conditions de $\mathrm{pH}$ où nous opérons ne permettent pas de doser quantitativement le TPN, TPNH et DPNH (BuRCH et al., I963).

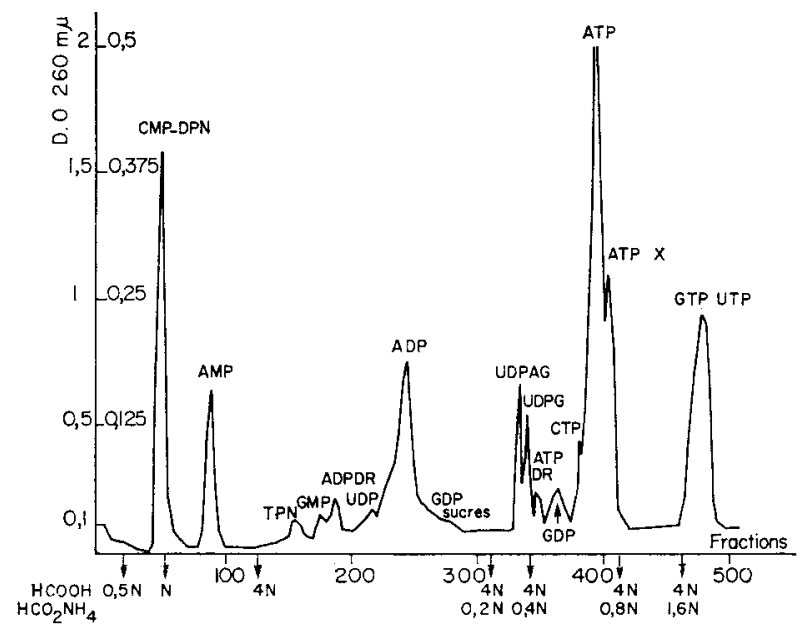

Fig. I. - Chromatogramine des nuléolides acido-solubles des intestins d'un lot de rats mâles âgés de 7,5 semaines. Colonne cylindrique de $30 \mathrm{~cm}$ de hiıteur, $6 \mathrm{~mm}$ de diamìtre intérieur, $50 \mathrm{~cm}^{3}$ de volume utile pouvant retenir 2500 D. O. (à $260 \mathrm{~m} u$ )

L'élution est effectuée à $0-4^{\circ} \mathrm{C}$ à l'aide d'un gradient exponentiel d'acide formique, puis acide formique-formiate d'ammonium

\section{Préparation et analyse des résidus}

Les résidus de l'extraction à l'ATC contiennent les protéines, les acides nucléiques, la plus grande partie des graisses et une partie des minéraux des organes traités.

\section{a) Extraction des lipides.}

Les résidus sont neutralisés au méthanol acétate de sodium $\mathrm{N}$ à $\mathrm{pH} \tau$; puis dégraissés par le mélange méthanol-chloroforme $(\mathrm{IV} / 2 \mathrm{~V}) \grave{a ̀ ~} \mathrm{pH}_{7}\left(\mathrm{P} / \mathrm{V}=\frac{\mathrm{I}}{25}\right)$. Trois traitements successifs sont effectués. Les résidus sont ensuite soumis à un lavage à l'éthanol Ioo suivi d'un lavage à l'éther sulfurique.Enfin, on les sèche sur Büchner, puis au dessiccateur. La poudre sèche est pesée, homogénéisée au broyeur à billes Dangoumeau et conservée à $-18^{\circ} \mathrm{C}$. Celle-ci ne contient plus que les protéines, les acides nucléiques et des sels minéraux.

b) Extraction des acides nucléiques de la poudre séchée et dégraissée.

Exiraction de l'ARN.

La méthode utilisée est celle de Schmidt et TANnhauser (I945) : l'ARN est isolé de l'ADN par une hydrolyse sodique.

Dans un bécher de $150 \mathrm{ml}$, on ajoute $50 \mathrm{ml}$ de $\mathrm{NaOH} 0,5 \mathrm{~N}$ à une quantité de poudre sèche, variable suivant la nature du résidu (700 $\mathrm{mg}$ pour l'intestin, I g pour le foie).

Les béchers sont placés au bain-marie à $37^{\circ}$ pendant 18 à 20 heures. Une agitation permanente est entretenue à l'aide d'agitateurs magnétiques. Les hydrolysats sont ensuite neutralisés à l'acide chlorhydrique. On précipite les protéines, et l'ADN par l'ATC (à $\left.\circ^{\circ} \mathrm{C}\right)$. Pour cela, on ajoute à chaque hydrolysat une solution d'ATC à $40 \mathrm{p}$. 100, en quantité suffisante pour obtenir une concentration finale de $10 \mathrm{p}$. $100(22 \grave{\mathrm{a}} 24 \mathrm{ml})$. Après Io minutes de contact à $0^{\circ} \mathrm{C}$, on centrifuge avec une 
centrifugeuse MSE refroidie, à $2300 \mathrm{~g}$ pendant to minutes. On recueille les surnageants, qui con* tiennent les mononucléotides constitutifs de l'ARN; on les filtre et on les amène à un volume choisi (200 ml) avec de l'eau bidistillée.

\section{Extraction de l'ADN.}

La méthode utilisée s'appuie sur le fait qu'une hydrolyse acide convenablement choisie de l'ADN libère quantitativement les bases puriques (LEvENE et BASS, I93 $\mathrm{I}$; CoLOWICK et KaplaN, I957) : le culot résultant de la précipitation de l'ADN et des protéines par l'ATC est hydrolysé par $5 \circ \mathrm{ml}$ de $\mathrm{ClO}_{4} \mathrm{H}$ o,5 $\mathrm{N}$, pendant 75 minutes au bain-marie bouillant. On arrête l'hydrolyse par refroidissement. Après une centrifugation de 10 minutes à $2300 \mathrm{~g}$ à $0^{\circ} \mathrm{C}$, les culots sonts lavés deux fois avec $3 \circ \mathrm{ml}$ de $\mathrm{ClO}_{4} \mathrm{II} 0,5 \mathrm{~N}$; les surnageants sont rassemblés, filtrés et ajustés à $\mathrm{I}_{5} \mathrm{O} \mathrm{ml}$ avec de l'eau bidistillée.

\section{c) Dosages des acides nucléiques.}

Ils sont faits d'après une méthode dérivée de celle de CoHs (I950-1955). $A R N$.

Les monoribonucléotides de l'extrait sont fixés sur une colonne de résine Dowex $\mathrm{I} \times$ Io (200-400 mesh) sous forme HCOO-. Les colonnes utilisées ont une hauteur utile de $25-30 \mathrm{~cm}$, un diamètre intérieur de $16 \mathrm{~mm}$ (volume utile $50-55 \mathrm{ml}$ ), une rétention normale de $2000 \mathrm{D}$. O. (densité optique). L'élution des monoribonucléotides est effectuée par deux systèmes de gradient exponentiel obtenus à l'aide d'une ampoule contenant les éluants successifs et d'un flacon mélangeur intermédiaire. Le ${ }_{\mathrm{I}}{ }^{\mathrm{er}}$ système constitué d'acide formique à concentration croissante élue successivement le CMP et l'AMP ; le deuxième, constitué d'un mélange d'acide formique et de formate d'ammonium élue successivement la pseudo-uridine-monosphosphate (pseudo-UMP), l'UMP et le GMP. Un collecteur recueille les éluats par fraction de Io $\mathrm{ml}$ (débit moyen de I $\mathrm{ml} / \mathrm{mn}$ ); on détermine ensuite les pics et la quantité correspondante (exprimée en $\mu$ moles) de chaque nucléotide par spectrophotométrie. On exprime la quantité d'ARN par la somme des nucléotides qui le constitue.

$A D N$.

Les produits de l'hydrolyse de l'ADN sont fixés sur une colonne de résine échangeuse de cations (AMBERLITE, IR I 20 200-400 mesh). Seules les bases puriques peuvent être fractionnées; mais les études de ChargafF (I953) et de nombreux auteurs ont montré que la somme des bases puriques de l'ADN est égale à la somme des bases pyrimidiques : la connaissance des quantités des bases puriques suffit donc pour obtenir la quantité d'ADN.

Les colonnes ont une hauteur utile de $30 \mathrm{~cm}$, un diamètre intérieur de $9 \mathrm{~mm}$ (volume utile $25 \mathrm{ml}$ ). La rétention optimum d'une telle colonne est de $250 \mathrm{D}$. O. à $260 \mathrm{~m} \mu$.

L'élution des bases puriques est effectuée sous pression (pompe Sigmamotor) à l'aide d'un gradient linéaire d'HCl (flacon principal $6 \mathrm{~N}$, flacon mélangeur $\mathrm{HCl} 0,75 \mathrm{~N}$ ). Le débit assuré par la pompe est de $5 \mathrm{ml} / \mathrm{minute}$. Un collecteur de fractions recueille l'éluat par fraction de $10 \mathrm{ml}$.

Les bases puriques sont dosées par spectrophotométrie (coefficients d'extinction molaire : guanine II,05 dans $\mathrm{HCl} 2,4 \mathrm{~N}$-adénine $\mathrm{II}, 7$ dans $\mathrm{HCl} 3,5 \mathrm{~N}$ à $260 \mathrm{~m} \mu$ ).

\section{Dosage de l'azote de la poudre sèche et dégraissée}

L'azote est dosé sur la poudre sèche et dégraissée par la méthode de Kjeldahl. La poudre ne contient plus comme source d'azote que des protéines et des acides nucléiques. La plus grande part de l'azote dosé étant fournie par les protéines ( 90 à 98 p. 100), on la désigne sous le terme d' " Azote protéic|ue ".

\section{II. - Traitements ET ANALYSES EFFECTUŔs SUR LES CARCASSES}

Les carcasses congelées à - I $8^{\circ} \mathrm{C}$ sont broyées au hachoir à viande. Deux broyages successifs, effectués le plus rapidement possible fournissent un hachis très fin d'où sont prélevés des échantillons, pour étudier :

\section{$I^{0}$ La composition globale des carcasses}

- Matières sèches: elles sont obtenues par chauffage à l'étuve à $98^{\circ} \mathrm{C}$ pendant 24 heures sur des échantillons pesant environ $5 \mathrm{~g}$.

- Cendres : on les obtient par calcination au four, à $530^{\circ} \mathrm{C}$ pendant $\mathrm{i} 5$ heures. 
- Protéines $(\mathrm{N} \times 6,25)$ : l'azote est dosé par la méthode Kjeldahl.

- Lipides : le taux des matières grasses est calculé par différence : lipides p. $100=100-$ (protéines p. I00 + eau p. 100 + cendres p. I00).

\section{$2^{\circ}$ Le contenu en $A D N$ et $A R N$ et " azote protéique "}

On pratique sur un prélèvement de $200 \mathrm{~g}$ de hachis, exactement les mêmes opérations d'extraction que sur les foies et les intestins. Mais les extraits acido-solubles n'ont pas été analysés. Seuls les dosages d'ADN, d'ARN el d'azote protéique ont été effectués. Les hydrolyses sont effectuées sur $2 \mathrm{~g}$ de poudre sèche et dégraissée.

\section{RÉSULTATS}

\section{Rappel des conventions adopiées}

I. Nombre de cellules d'un tissu, d'un organe, d'un organisme $=k \times \mathrm{ADN}$ total $(\mu \mathrm{m})$,

2. Taille des cellules $=\frac{\text { poids frais }(\mathrm{g})}{\mathrm{ADN} \text { total }(\mu \mathrm{m})}=p$.

3. Azote protéique par cellule $=\frac{\text { azote protéique }(\mathrm{mg})}{\operatorname{ADN} \text { total }(\mu \mathrm{m})}$.

4. ARN moyen par cellule $=\frac{\operatorname{ARN} \text { total }(\mu \mathrm{m})}{\operatorname{ADN} \text { total }(\mu \mathrm{m})}$.

5. Nucléotides par cellule $=\frac{\text { nucléotide (D.O.) }}{\operatorname{AI}) \text { N (um) }}$.

\section{INTESTIN GRÊLE (tab1. 3 et 4 )}

Poids frais : jusqu'à 5 semaines, l'intestin grêle croît proportionnellement à l'ensemble du corps (environ 6 p. Ioo du poids vif). A partir de cet âge, son poids continue à augmenter mais ne constitue qu'une fraction de plus en plus faible du poids total de l'animal (2,44 p. Ioo à I7 semaines).

Le poids de l'intestin grêle sec et dégraissé suit une évolution tout à fait parallèle à l'évolution du poids frais : en effet, le rapport $\frac{\text { poids sec et dégraissé }}{\text { poids frais }} \times$ roo reste toujours très voisin de 10,5 .

Le nombre de cellules: (ADN total) (tabl. 3), est multiplié par $2,4 \mathrm{I}$ entre la $3^{\mathrm{e}}$ et la $5^{\text {e }}$ semaine. L'augmentation est importante jusqu'à 7,5 semaines, puis, quoique devenant faible, se poursuit pendant l'ensemble de la période.

Ia taille des cellules : ( $\left.\frac{\text { poids frais de l'intestin grêle }}{A D N \text { total }}\right)$ augmente d'une manière appréciable entre 3 et 5 semaines et ne subit plus d'évolution appréciable au-delà de 5 semaines.

L'azote protéique par cellule : $\left(\frac{\text { azote protéique }}{\operatorname{ADN}}\right)$ augmente de $5 \mathrm{p}$. Ioo de 3 
à 5 semaines (de I,I4 à $I, 20$ ), semble demeurer stable de 5 à 7,5 semaines $(I, 20)$ pour augmenter légèrement ensuite. Mais ces variations qui n'excèdent pas I0,5 p. IOO sur l'ensemble de la période, demeurent de faible importance.

\section{TABLEAU 3}

Intestin grêle. Évolution en fonction de l'âge de certaines caractéristiques chez le rat albinos en croissance

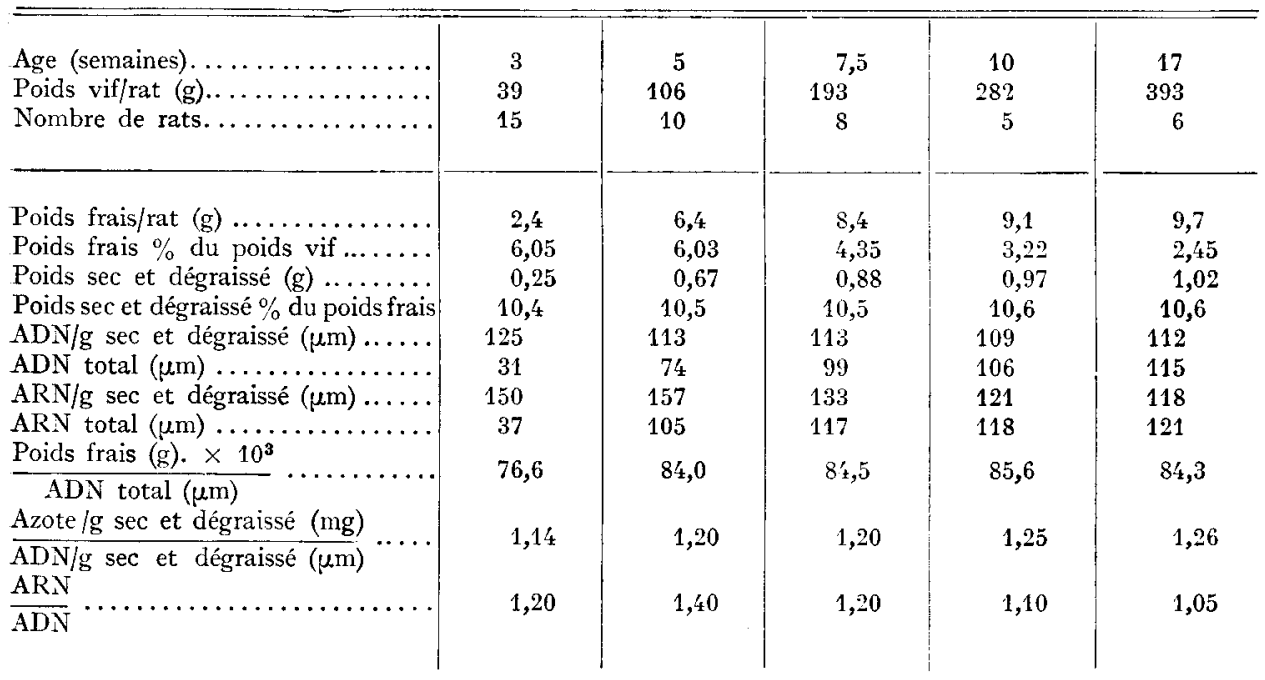

Les données ci-dessous sont calculées en attribuant la valeur 100 à certains résultats concernant les animaux de 3 semaines

\begin{tabular}{|c|c|c|c|c|c|}
\hline Poids frais $\ldots \ldots \ldots \ldots \ldots \ldots \ldots$ & 100 & 266 & 350 & 379 & 404 \\
\hline ADN total $\ldots \ldots \ldots \ldots \ldots \ldots$ & 100 & 242 & 322 & 345 & 374 \\
\hline$\frac{\text { Poids frais }}{\mathrm{ADN}^{2}} \ldots \ldots \ldots \ldots \ldots \ldots$ & 100 & 110 & 110 & 112 & 110 \\
\hline Azote /g sec et dégraissé & 100 & 105 & 105 & 110 & 110,5 \\
\hline $\begin{array}{l}\mathrm{ADN} / \mathrm{g} \text { sec et dégraissé } \\
\mathrm{ARN} \text { total } \ldots \ldots \ldots \ldots \ldots \ldots\end{array}$ & 100 & 283 & 315 & 318 & 325 \\
\hline
\end{tabular}

L'ARN total est multiplié par 2,83 (plus vite que 1'ADN) entre la $3^{\mathrm{e}}$ et la $5^{\mathrm{e}}$ semaine, augmente encore légèrement jusqu'à 7,5 semaines, et devient ensuite pratiquement stationnaire.

L'ARN par cellule : $\left(\frac{A R N}{A D N}\right)$ croît de $I, 2$ à I,4 entre 3 et 5 semaines, et décroît ensuite progressivement jusqu'à $x, 05$.

Nucléotides acido-solubles : (tabl. 4). Nous avons dosé I6 nucléotides acidosolubles.

- La quantité par cellule $\left(\frac{D . O}{A D N}\right)$ de $I_{4}$ d'entre eux, passe par un maximum à 5 semaines; l'ATP et l'IMP font exception : 
Io 1'ATP atteint un palier au stade de 5 semaines et reste pratiquement stablejusqu'à la fin de la période considérée ;

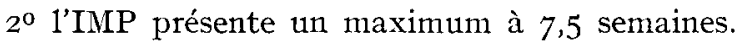

- Six des 16 composés étudiés se trouvent en quantité minimum à 7.5 semaines : (UMP - GMP - AMP - UDPAG — GDP sucre - - ADP).

\section{TABLEAU 4}

Intestin grêle. Érolution suivant l'áge de la teneur par cellule en nuclíotides acido-solubles (Les données sont exprimées en $\frac{\mathrm{DO}}{\mathrm{ADN}} \times \mathrm{ro}^{2}$ )

\begin{tabular}{|c|c|c|c|c|c|}
\hline Age (semaines) $\ldots \ldots \ldots \ldots \ldots \ldots$ & 3 & 5 & 7,5 & 10 & $17]$ \\
\hline 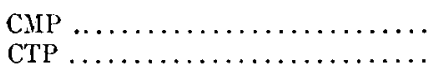 & $\begin{array}{l}1,3 \\
0\end{array}$ & $\begin{array}{l}3 \\
3,6\end{array}$ & $\begin{array}{l}1,8 \\
3,1\end{array}$ & $\begin{array}{l}1,0 \\
2,0\end{array}$ & $\begin{array}{l}2,1 \\
2,6\end{array}$ \\
\hline$\Sigma c \ldots \ldots \ldots \ldots \ldots \ldots \ldots \ldots \ldots$ & 1,3 & 6,6 & 4,9 & 3,0 & 4,7 \\
\hline 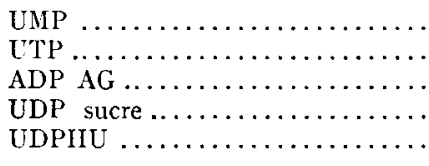 & $\begin{array}{r}4,5 \\
14,6 \\
9,7 \\
6,9 \\
0\end{array}$ & $\begin{array}{r}6,8 \\
20,1 \\
14,5 \\
9,0 \\
4,2\end{array}$ & $\begin{array}{c}0 \\
21,9 \\
11,3 \\
7,7 \\
0\end{array}$ & $\begin{array}{c}0 \\
18,4 \\
11,6 \\
7,3 \\
4\end{array}$ & $\begin{array}{r}2,1 \\
15,7 \\
12,5 \\
6,8 \\
0\end{array}$ \\
\hline$\Sigma \mathrm{U} \ldots \ldots \ldots \ldots \ldots \ldots \ldots \ldots \ldots \ldots$ & 35,7 & 54,6 & 40,9 & 41,3 & 37,1 \\
\hline 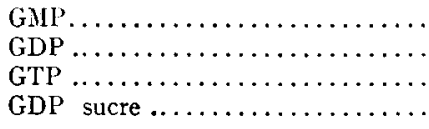 & $\begin{array}{c}1,8 \\
6,8 \\
14,5 \\
0\end{array}$ & $\begin{array}{r}4,6 \\
8,0 \\
17,5 \\
3,5\end{array}$ & $\begin{array}{r}2,1 \\
7,2 \\
16,5 \\
0\end{array}$ & $\begin{array}{r}3,8 \\
5,8 \\
10,6 \\
5,3\end{array}$ & $\begin{array}{r}3,1 \\
5,1 \\
15,6 \\
2,9\end{array}$ \\
\hline$\Sigma \mathrm{G} \ldots \ldots \ldots \ldots \ldots \ldots \ldots$ & 23,1 & 33,6 & 25,8 & 25,5 & 26,7 \\
\hline 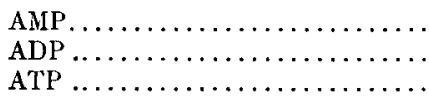 & $\begin{array}{r}7,2 \\
16,6 \\
100,2\end{array}$ & $\begin{array}{r}29,7 \\
42,0 \\
119,7\end{array}$ & $\begin{array}{r}11,7 \\
30,3 \\
122\end{array}$ & $\begin{array}{r}23,6 \\
38,9 \\
117,7\end{array}$ & $\begin{array}{r}51,2 \\
35,6 \\
118,3\end{array}$ \\
\hline$\Sigma A \ldots \ldots \ldots$ & 121,0 & 191,4 & $16^{\prime}, 0$ & 180,2 & 205,1 \\
\hline 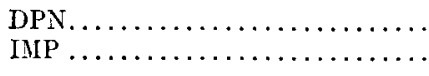 & $\begin{array}{r}15,1 \\
0,9\end{array}$ & $\begin{array}{r}31,1 \\
2,1\end{array}$ & $\begin{array}{r}22,,^{\prime} \\
2,5\end{array}$ & $\begin{array}{r}19,8 \\
1,4\end{array}$ & $\begin{array}{r}25,2 \\
1,5\end{array}$ \\
\hline Total des nucléotides. & 200 & 319,4 & 260,5 & 271,2 & 300,2 \\
\hline
\end{tabular}

Nous ne trouvons dans cette série que des nucléotides mono- et diphosphates.

- Sept des I6 composés se trouvent en quantité minimum à ro semaines : (CTP - GTP - IMP - DPN). GDP).

- Trois décroissent constamment de 3 à I7 semaines : (UTP — UDP sucre et

- Un composé (UDPHU) subit des variations brusques. 
En résumé, nous constatons en général que la quantité de nucléotides contenus dans chaque cellule de l'intestin grêle passe par :

une phase ascendante de 3 à 5 semaines;

une phase descendante de 5 à 7,5 semaines,

une nouvelle phase lentement ascendante ensuite.

La dernière ligne du tableau 4 , qui fournit pour chaque lot la somme de tous les nucléotides étudiés exprimés en $\frac{\mathrm{DO}}{\mathrm{ADN}}$ fournit une bonne représentation de 1'évolution la plus classique.

$$
\text { II. - Fore, (tabl. } 5 \text { et } 6 \text { ) }
$$

Le cas du foie est plus difficile à analyser du fait, qu'en plus de types de tissus variés, il contient de nombreux noyaux polyploïdes, et que le taux de polyploïdie varie en fonction de 1'âge. Nous reviendrons sur ce point au cours de la discussion.

\section{TABLEAU 5}

Foie

Evolution en fonction de l'âge de certaines caractéristiques chez le rat albinos en croissance.

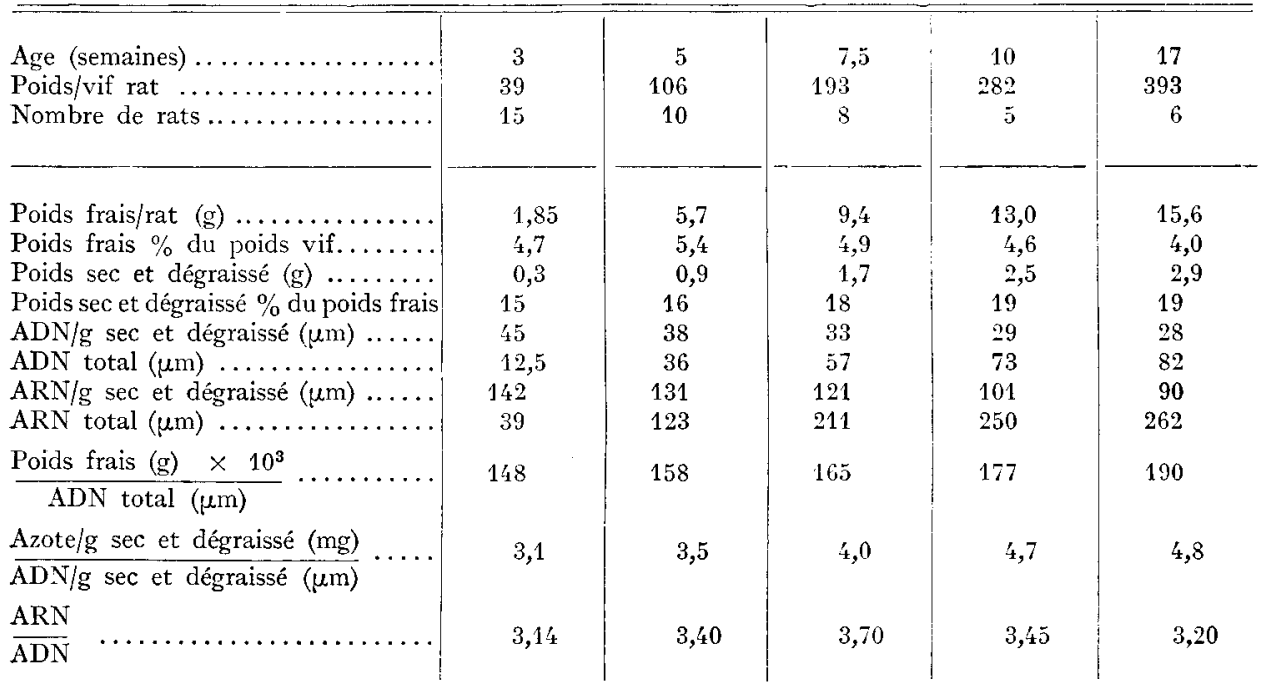

Les données ci-dessous sont calculées en attribuant la valeur 100 à certains résultats concernant les animaux de 3 semaines

\begin{tabular}{|c|c|c|c|c|c|}
\hline $\begin{array}{l}\text { Poids frais } \ldots \ldots \ldots \ldots \ldots \ldots \ldots \ldots \ldots \ldots \ldots \ldots \ldots \ldots \\
\text { ADN total } \ldots \ldots \ldots \ldots \ldots \ldots \ldots\end{array}$ & $\begin{array}{l}100 \\
100\end{array}$ & $\begin{array}{l}308 \\
288\end{array}$ & $\begin{array}{l}508 \\
456\end{array}$ & $\begin{array}{l}703 \\
580\end{array}$ & $\begin{array}{l}843 \\
654\end{array}$ \\
\hline$\frac{\text { Poids }}{\text { ADN }}$ trais $\cdots$ & 100 & 107 & 111 & 119 & 128 \\
\hline$\frac{\text { Azote/g sec et dégraissé }}{\text { Azote } / g \text { sec et dégraissé }} \ldots \ldots \ldots$ & 100 & 113 & 129 & 153 & 155 \\
\hline ARN total .. & 100 & 314 & 539 & $6{ }_{1}^{\prime} 0$ & 670 \\
\hline
\end{tabular}


Poids frais : le poids du foie ne cesse pas d'augmenter pendant toute la périodeétudiée. Il croît plus rapidement que l'ensemble du corps de 3 à 5 semaines, à peu. près proportionnellement de 5 à ro semaines. Finalement de 3 à I 7 semaines, le poids vif de l'animal a été multiplié par ro, le poids du foie par 8,43 seulement (tabl. 5).

Le foie représente malgré tout environ $4 \mathrm{p}$. Ioo du poids vif de l'animal âgé de $\mathbf{I} 7$ semaines (tabl. 5).

\section{TABLEAU 6}

\section{Foie}

Évolution suivant l'âge de la teneur par cellule en nucléotides acido-solubles (Les données sont exprimées en $\frac{\mathrm{DO}}{\mathrm{ADN}} \times$ Io)

\begin{tabular}{|c|c|c|c|c|c|}
\hline Age (semaines) $\ldots \ldots \ldots \ldots \ldots \ldots$ & 3 & 5 & 7,5 & 10 & 17 \\
\hline 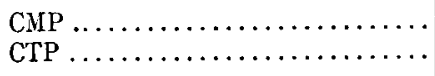 & $\begin{array}{l}1,2 \\
0,2\end{array}$ & $\begin{array}{l}1,0 \\
0,3\end{array}$ & $\begin{array}{l}0,9 \\
0,4\end{array}$ & $\begin{array}{l}1,0 \\
0\end{array}$ & $\begin{array}{l}0,7 \\
0,2\end{array}$ \\
\hline$\Sigma \mathrm{c} \ldots \ldots \ldots \ldots \ldots \ldots \ldots \ldots \ldots \ldots \ldots$ & 1,4 & 1,3 & 1,3 & 1,0 & 0,9 \\
\hline 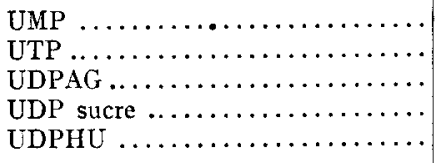 & $\begin{array}{l}6,3 \\
0,6 \\
4,5 \\
6,7 \\
0\end{array}$ & $\begin{array}{l}8,9 \\
2,5 \\
3,0 \\
6,1 \\
1,3\end{array}$ & $\begin{array}{l}7,9 \\
5,4 \\
4,7 \\
8,9 \\
3,5\end{array}$ & $\begin{array}{l}8,4 \\
1,9 \\
5,8 \\
9,6 \\
0\end{array}$ & $\begin{array}{l}9,2 \\
1,9 \\
5,0 \\
9,0 \\
0\end{array}$ \\
\hline$\Sigma U$ & 18,1 & 21,8 & 30,4 & 25,7 & 25,1 \\
\hline 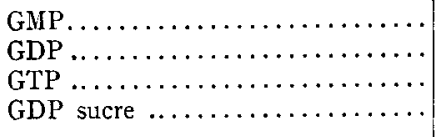 & $\begin{array}{l}3,1 \\
0,7 \\
1,2 \\
0\end{array}$ & $\begin{array}{l}2,8 \\
2,4 \\
3,1 \\
0,9\end{array}$ & $\begin{array}{l}2,2 \\
3,3 \\
3,3 \\
3,4\end{array}$ & $\begin{array}{l}5,3 \\
2,1 \\
1,2 \\
2,4\end{array}$ & $\begin{array}{l}1,3 \\
1,6 \\
1,0 \\
4,7\end{array}$ \\
\hline$\Sigma G \ldots \ldots \ldots \ldots \ldots$ & 5,0 & 9,2 & 12,2 & 11,0 & 8,6 \\
\hline 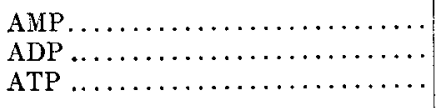 & $\begin{array}{l}14,6 \\
12,1 \\
14,6\end{array}$ & $\begin{array}{l}16,0 \\
21,8 \\
25,5\end{array}$ & $\begin{array}{l}14,4 \\
30,7 \\
35,2\end{array}$ & $\begin{array}{l}30,8 \\
35,2 \\
22,8\end{array}$ & $\begin{array}{l}29,3 \\
19,7 \\
18,3\end{array}$ \\
\hline$\Sigma A \ldots \ldots \ldots \ldots \ldots \ldots \ldots$ & 41,3 & 63,3 & 80,3 & 88,8 & 67,3 \\
\hline 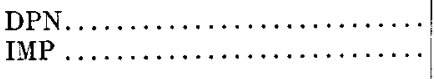 & $\begin{array}{r}13,6 \\
2,6\end{array}$ & $\begin{array}{r}19,6 \\
2,8\end{array}$ & $\begin{array}{r}22,9 \\
\mathbf{3}, 9\end{array}$ & $\begin{array}{r}23,1 \\
6,9\end{array}$ & $\begin{array}{r}28,6 \\
4,7\end{array}$ \\
\hline Total des nucléotides ... & 82,0 & 118,0 & 151,0 & 156,5 & 133,4 \\
\hline
\end{tabular}

- Le poids du foie sec et dégraissé croît constamment et le rapport poids du foie frais téines dans l'organe, croît régulièrement de 3 à Io semaines, pour rester à peu près stationnaire par la suite (tabl. 5).

Lu nombre de cellules augmente très rapidement jusqu'à ro semaines, plus lentement ensuite. 
La taille des cellules : ( $\frac{\text { poids frais du foie }}{\mathrm{ADN} \text { total }}$ ) augmente de 3 à I7 semaines, mais surtout de 3 à Io semaines.

L'azote protéique par cellule : ( $\left.\frac{\text { azote protéique }}{\mathrm{ADN}}\right)$ croit jusqu'à ro semaines et reste stable ensuite. Ceci ne fait d'ailleurs que confirmer ce que nous avons dit plus haut à propos du rapport $\frac{\text { poids sec dégraissé }}{\text { poids frais }}$.

L'ARN total se synthétise de façon intense jusqu'à 7,5 semaines en quantité proportionnellement plus importante que l'ADN. Au-delà de ce temps, la quantité d'ARN de l'organe augmente plus lentement pour devenir presque stable au-delà de ro semaines.

L'ARN par cellule : $\left(\frac{A R N}{A D N}\right)$ augmente de 3 à 7,5 semaines (de 3, I4 à 3,70) pour décroître ensuite jusqu'à 3,20 à I7 semaines.

Nucléotides acido-solubles (tabl. 6) : les nucléotides acido-solubles du foie obéissent au cours de la croissance à des lois différentes de celles de l'intestin grêle.

Nous constatons, qu'entre 3 à I 7 semaines :

- Sept des composés dosés présentent un maximum à 7,5 semaines (CTP - UTP - GTP - ATP - GDP - GDP sucre - UDPHU).

Nous trouvons dans cette série tous les nucléotides triphosphates et pas un seul nucléotide monophosphate.

- Six présentent un maximum à ro semaines (ADP - UDPAG - UDP sucre - GMP - AMP - IMP).

- Les quantités de DPN ne cessent d'augmenter de 3 à I7 semaines, en marquant toutefois un palier entre 7,5 et Io semaines.

- Le CMP ne varie guère au cours de la période.

- L'UMP semble atteindre un certain équilibre dès 5 semaines.

En résumé, le plus souvent la quantité des divers nucléotides associés à chaque noyau atteint un maximum vers 7,5 ou ro semaines.

Il est intéressant de noter la singularité de 1'évolution du DPN dont la quantité/noyau est une fonction croissante du temps de 3 à I 7 semaines. Ceci est en accord avec les résultats obtenus par CAIGER et MORTON (Ig62) sur moutons et rats, et par BuRCH et al. (1964) sur rats.

\section{III. - CARCaSse (tabl. 7 et 8 )}

Poids frais : pendant la période étudiée, le poids de carcasse a été multiplié par Io,4; le gain de poids est beaucoup plus rapide au cours de la première moitié de la période $(224 \mathrm{~g})$ contre $104 \mathrm{~g}$ seulement au cours de la deuxième moitié.

\section{Composition globale.}

Eau. - Pendantla période étudiée, la proportion d'eau dans les carcasses diminue de $7 \mathrm{r}, 4 \mathrm{p}$. roo pour des animaux de 3 semaines à $56,7 \mathrm{p}$. Ioo pour des animaux de I7 semaines. Cette diminution devient particulièrement rapide au-delà de 7,5 semaines. 


\section{TABLEAU 7 \\ Carcasse \\ Évolution de la composition globale au cours de la croissance}

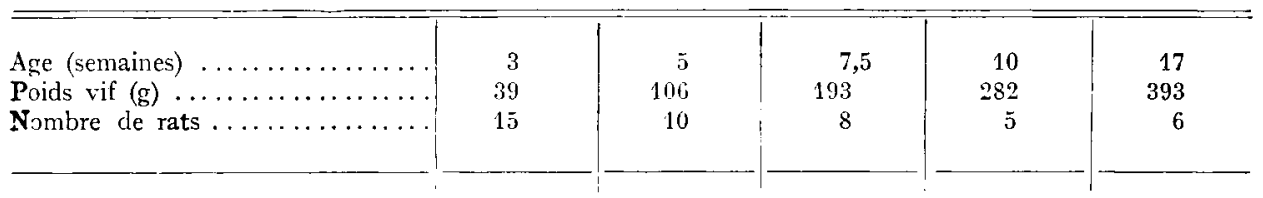

$g$ p. $100 \mathrm{~g}$ de poids vif

\begin{tabular}{|c|c|c|c|c|c|}
\hline Ealı & $71,{ }^{\prime}$ & 69,6 & $66,,^{\prime}$ & 61,1 & 56,7 \\
\hline Protéines $(\mathrm{N} \times 6,25)$ & 17,0 & 17,6 & 18,5 & 19,3 & 19,7 \\
\hline Cendres ........... & 2,7 & 2,6 & 3,3 & 3,4 & 3,1 \\
\hline Lipides (par différence). & 8,9 & 10,2 & 11,8 & 16,2 & 20,5 \\
\hline
\end{tabular}

\section{TABLEAU $S$}

Carcasse. Evolution en fonction de l'âge de certaines caractéristiques ches le rat albinos en croissance

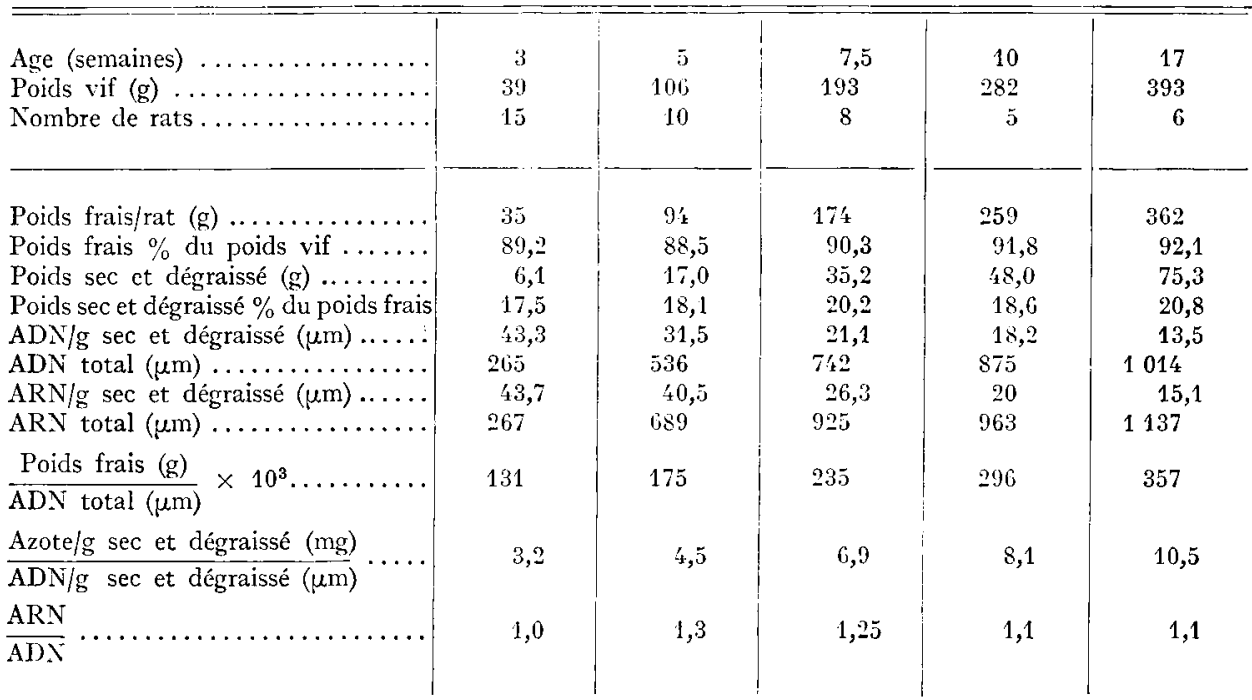

Les données ci-dessous sont calculées en attribuant la valeur 100 à certains résultats concernant les animaux de 3 semaines

\begin{tabular}{|c|c|c|c|c|c|}
\hline Poids frais & 100 & 269 & 500 & 743 & 1040 \\
\hline ADN total ...... & 100 & 202 & 280 & 330 & 382 \\
\hline$\frac{\text { Poids frais }}{A D N}$ & 100 & 133 & 179 & 225 & 272 \\
\hline$\frac{\text { Azote/g sec et dégraissé }}{\mathrm{ADN} / \mathrm{g} \text { sec et dégraissé }}$ & 100 & 141 & 216 & 253 & 328 \\
\hline ARN total $\ldots \ldots$. & 100 & 258 & 346 & 360 & 426 \\
\hline
\end{tabular}


Lipides. - La proportion de lipides augmente lentement de 3 à 7,5 semaines. Au-delà de cet âge, l'engraissement devient rapide, particulièrement entre 7,5 et Io semaines.

Protéines $(\mathrm{N} \times 6,25)$. - L a proportion des protéines augmente presque linéairement de 3 à ro semaines puis lentement de Io à $I 7$ semaines.

Cendres. - La part qui revient aux cendres dans la composition des carcasses demeure évidemment toujours faible. Il n'en reste pas moins qu'elle croît d'une façon continuelle de 3 à Io semaines (de 2,7 à 3,4 p. Ioo). Elle décroît ensuite sans doute quand l'ossification de l'animal est achevée.

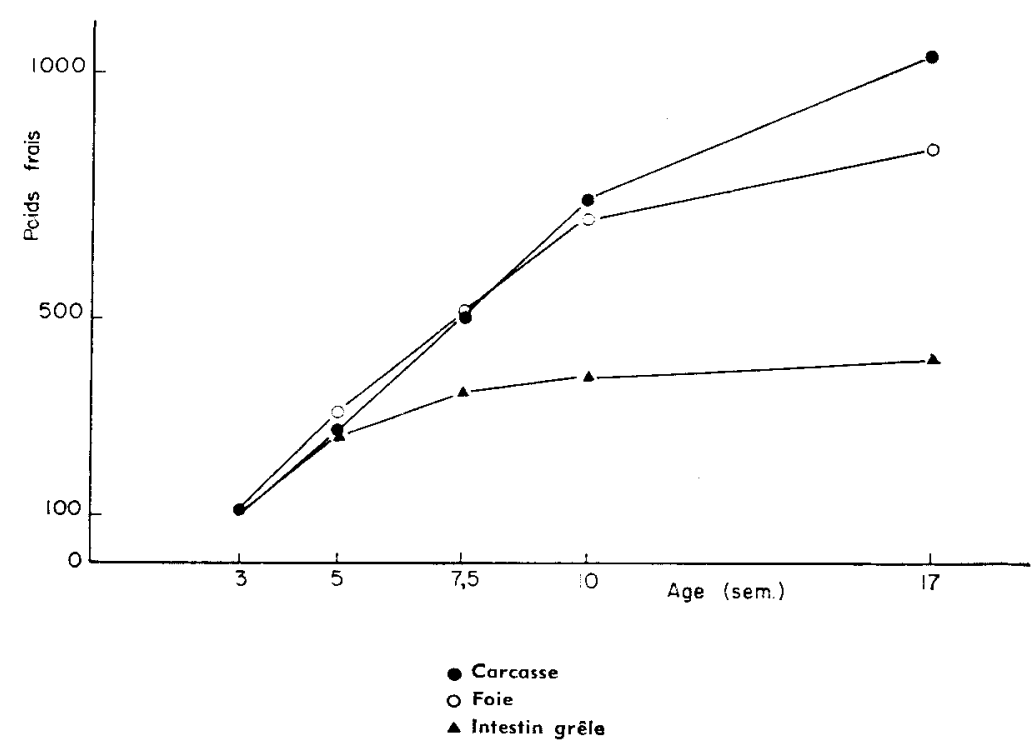

FIG. 2. - Croissance pontérale de l'in'estin grète, du foie et de la carcasse du rat blanc en fonction de l'âge, en attribuant la valewr os aux données correspondant aux animaux de 3 semaines

Le nombre de cellules est multiplié par 2,02 entre 3 et 5 semaines; par $\mathrm{I}, 38$ entre 5 et 7,5 semaines; I,I 7 entre 7,5 et Io semaines; I,I 6 entre Io et I 7 semaines.

La taille des cellules : ( $\frac{\text { poids frais de carcasse }}{\text { ADN total }(\mu m)}$ ) est multipliée par $\mathrm{I}, 33$ entre 3 et 5 semaines; par I,34 entre 5 et 7,5 semaines ; par 1,26 entre 7,5 et ro semaines et $\mathrm{I}, 22$ entre Io et $\mathrm{I} 7$ semaines.

L'azote protéique par cellule : $\left(\frac{\text { azote protéique }(\mathrm{mg})}{\mathrm{ADN}(\mu \mathrm{m})}\right)$ augmente proportionnellement plus rapidement que la taille des cellules, de 3 à 7,5 semaines. Entre 7,5 et ro semaines, la quantité d'azote protéique par cellule et la taille des cellules augmentent sensiblement de la même façon.

L'ARN total augmente très rapidement entre 3 et 7,5 semaines puis tend à atteindre une quantité stable.

L'ARN par cellule : $\left(\frac{\mathrm{ARN}}{\mathrm{ADN}}\right)$ passe par un maximum ( $\mathrm{I}, 3$ à 5 semaines) pour redescendre ensuite ( $I, I$ à Io semaines).

Annales de Biologie animale, -1965 . 


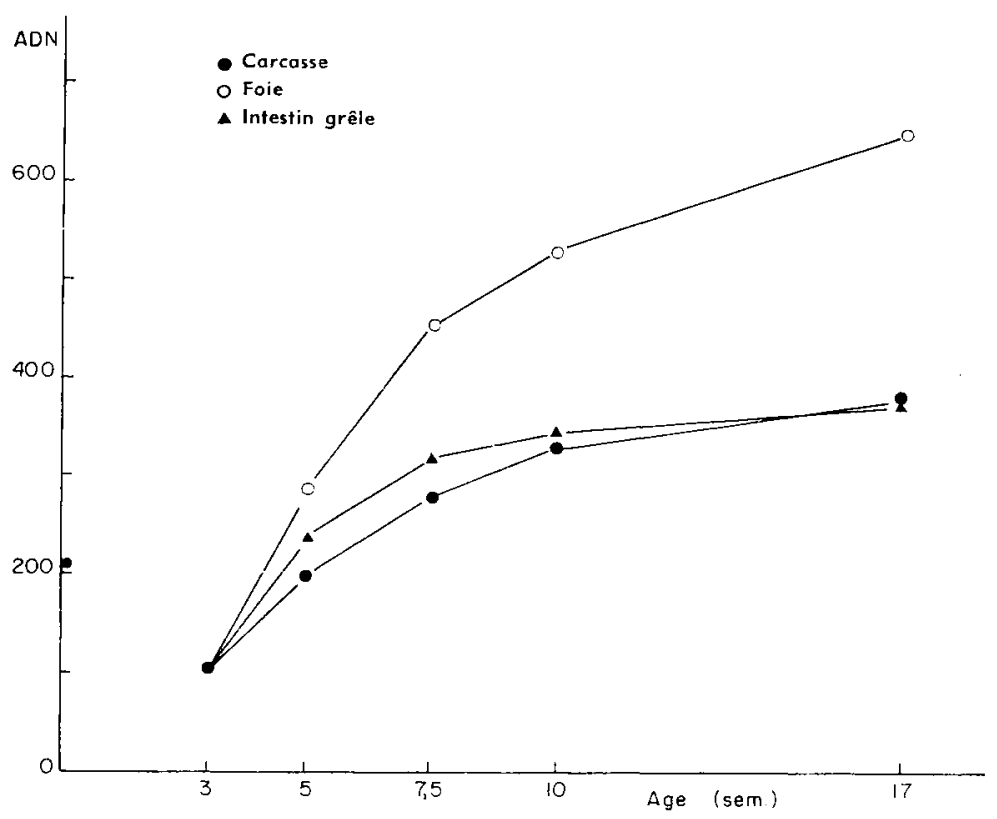

FIG.3. - Evolution en fonction de l'àge de la teneur totale en ADN de l'intestint gréle. du foie et de la carcasse du rat blanc en croissance, en altribuanl la raleur roo aux données correstondani aux animaux de 3 semaines.

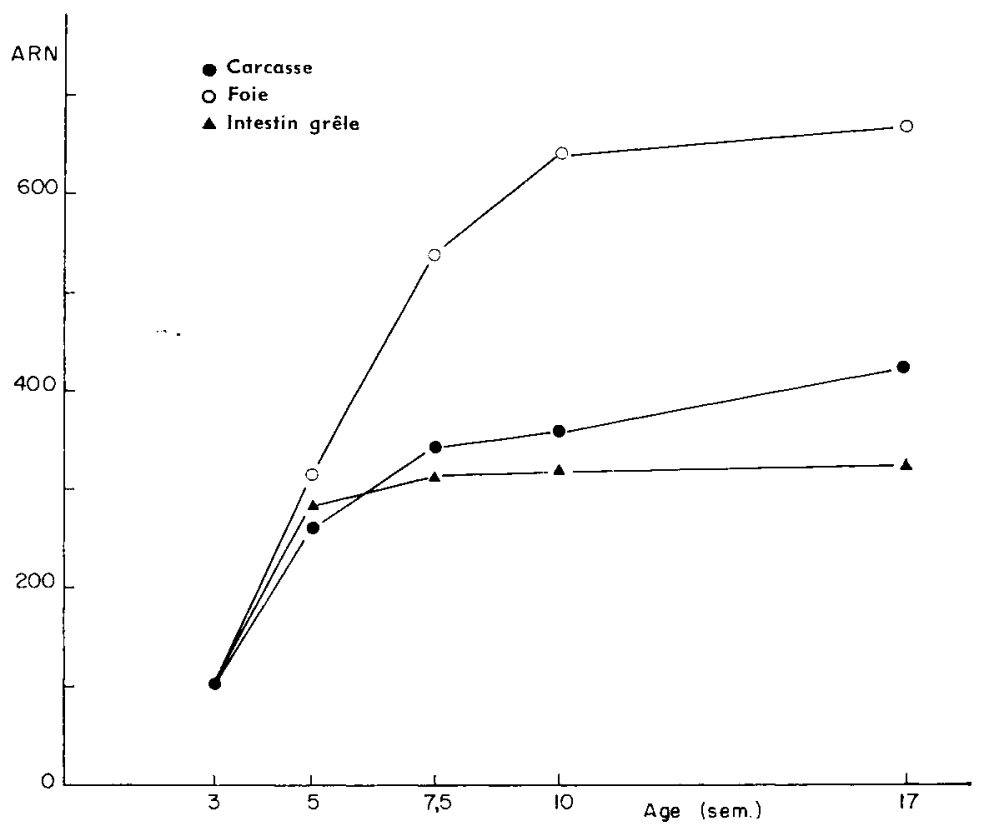

FIG. 4. - Evolution en fonction de l'âge de la teneur totale en ARN du foie, de l'intestin grêle et de la carcasse du rat blanc en croissance, attribuant la valettr 100 aux données correspondant aux animaux agés de 3 semaines 


\section{DISCUSSION}

\section{Principes}

a) Pour cette étude de la croissance en fonction de l'âge de l'intestin grêle, du foie et de la carcasse du rat, 5 lots d'animaux mâles ont été utilisés.

Nos méthodes d'analyse nécessitent des prélèvements d'au moins $30 \mathrm{~g}$ de tissu frais (ce qui permet d'obtenir environ $3 \mathrm{~g}$ d'intestin grêle, 5-6 $\mathrm{g}$ de foie, 5-6 $\mathrm{g}$ de carcasse sous forme de poudre sèche et dégraissée). Il a donc été nécessaire, de grouper les organes de plusieurs rats en vue de leur analyse. Ces organes sont obtenus à partir d'animatux homogènes ayant présenté une croissance très proche de la croissance moyenne d'une population plus importante.

b) L'interprétation des résultats repose sur le principe que le nombre de noyaux d'un tissu ou d'un ensemble de tissus est proportionnel à la quantité d'ADN que contient ce tissu ou ensemble de tissus. Ce principe découle de la loi de Borvin et VENDRELY (I948) citée dans l'introduction; il permet de mesurer les variations du nombre de noyaux d'un organe ou d'un tissu en fonction de l'âge.

La méthode est en défaut si des noyaux deviennent polyploïdes au cours de la croissance; dans ce cas, la quantité moyenne d'ADN par noyau varie avec l'âge. Le foie présente cette particularité, comme nous le verrons ci-dessous.

On peut objecter aussi que les noyaux sur le point de se diviser doublent leur teneur en ADN (SWIFT, I953; CARRIÈRE, I960). A cela on peut répondre que «l'ADN total inclue non seulement 1'ADN des noyaux présents mais aussi l'ADN des noyaux en puissance " (ENESCO et LEBLOND, Ig62) lesquels auraient acquis quelques heures plus tard une existence propre, si l'abattage n'avait pas eu lieu.

Le reproche le plus fondé qu'on puisse faire à la méthode est d'un autre ordre. En effet, la croissance d'un organe comme l'intestin grêle ou le foie, ou d'un ensemble hétérogène comme ce que nous avons appelé "carcasse" est la résultante de la croissance respective des tissus constitutifs (musculaires, osseux, conjonctifs, glandulaires, muqueux, etc.). Comme l'a justement fait remarquer ENEsco la méthode utilisée ne permet pas de déterminer la part revenant à chacun de ces tissus.

Elle a cependant l'avantage, d'approcher de plus près, les mécanismes biologiques fondamentaux, que ne peuvent le faire les méthodes par dissections, pesées et analyse élémentaire.

II. Etude de l'influence relative de la division et du grandissement cellulaires sur la croissance

Appelons :

$\begin{array}{lllllll}\text { A la période allant de } & 3 & \text { à } & 5 & \text { semaines } \\ \text { B } & - & - & 5 & \text { à } & 7,5 & - \\ \text { C } & - & - & 7,5 & \text { à } & \text { IO } & - \\ \text { D } & - & - & \text { Io } & \text { à } & \text { I } 7 & -\end{array}$


soit 1'expression :

que l'on peut écrire :

$$
\mathrm{P}=\mathrm{N} \times p
$$

ou encore :

$$
\mathrm{P}=k \mathrm{ADN} \times p
$$

$$
\log \mathrm{P}=\log \mathrm{ADN}+\log p+\log \mathrm{K}
$$

Prenons la dérivée logarithmique par rapport au temps de cette expression :

$$
\frac{p^{\prime}}{\mathrm{P}}=\frac{\mathrm{ADN}^{\prime}}{\mathrm{ADN}}+\frac{p^{\prime}}{p}
$$

ou encore :

$$
\frac{\mathbf{I}}{\mathrm{P}} \frac{d \mathrm{P}}{d t}=\frac{\mathrm{I}}{\mathrm{ADN}} \frac{d(\mathrm{ADN})}{d t}+\frac{\mathrm{I}}{p} \frac{d p}{d t}
$$

La relation (3) exprime que : la variation instantanée relative de poids d'un organe ou d'un tissu (ou d'un ensemble de tissus), est égale à la somme de la variation instantanée relative du nombre de cellules dont il est constitué et de la variation instantanée relative de la taille de chaque cellule.

Il est évidemment pratiquement impossible de mesurer des variations de $P$, $\mathrm{ADN}$ et $p$ pendant des périodes $d t$ arbitrairement petites. Aussi on ne peut utiliser la relation (3) que sous la forme

$$
\frac{\mathrm{I}}{\mathrm{P}} \frac{\Delta \mathrm{P}}{\Delta t}=\frac{\mathrm{I}}{\mathrm{ADN}} \frac{\Delta(\mathrm{ADN})}{\Delta t}+\frac{\mathrm{I}}{\bar{p}} \frac{\Delta p}{\Delta t}
$$

Dans le cas présent :

a) $\Delta t$ représentera successivement la durée exprimée en jours de chacune des périodes $\mathrm{A}, \mathrm{B}, \mathrm{C}$ et $\mathrm{D}$.

b) Soient :

$$
\begin{aligned}
& \mathrm{P}_{1}, \operatorname{ADN}_{1}, p_{1} \\
& \mathrm{P}, \operatorname{ADN}, p \\
& \mathrm{P}_{2}, \mathrm{ADN}_{2}, p_{2} .
\end{aligned}
$$

les caractéristiques du tissu étudié, au début, au milieu et à la fin de chaque période ;

$\mathrm{P}_{1}, \mathrm{ADN}_{1}, p_{1}, \mathrm{P}_{2}, \mathrm{ADN}_{2}, p_{2}$ sont connues.

En supposant que les variations des trois caractéristiques soient linéaires en fonction du temps à l'intérieur de chaque période, on obtient :

$$
\begin{aligned}
\mathrm{P} & =\frac{\mathrm{P}_{1}+\mathrm{P}_{2}}{2} \quad \mathrm{ADN}=\frac{\mathrm{ADN}_{1}+\mathrm{ADN}_{2}}{2} & p=\frac{p_{1}+p_{2}}{2} \\
\Delta \mathrm{P}=\mathrm{P}_{2}-\mathrm{P}_{1} & \Delta(\mathrm{ADN})=\mathrm{ADN}_{2}-\mathrm{ADN}_{1} & \Delta p=p_{2}-p_{1}
\end{aligned}
$$

L'expression (4) peut être traduite ainsi :

- la variation relative quotidienne de poids d'un organe, d'un tissu (ou d'un ensemble de tissus) est égale à la somme de la variation relative quotidienne du nombre de cellules et de la variation relative quotidienne de la taille de chaque cellule. 
TABLEAU 9

Croissance relative quotidienne $\frac{1}{P} \times \frac{\Delta P}{\Delta \mathrm{t}}$, augmentation relative quotidienne du nombre de cellules $\frac{1}{A D N} \times \frac{\Delta A D N}{\Delta \mathrm{t}}$, grandissement quotidien relatif $\frac{1}{\mathrm{p}} \times \frac{\Delta \mathrm{p}}{\Delta \mathrm{t}}$ de l'intestin grêle, du foie et de la carcasse du rat en croissance

\begin{tabular}{|c|c|c|c|c|c|}
\hline & Périodes & $\begin{array}{c}\mathrm{A} \\
3 \text { à } 5 \text { semaines } \\
(14 \mathrm{j})\end{array}$ & $\begin{array}{c}\mathrm{B} \\
5 \text { à } 7,5 \text { semaines } \\
(17,5 j)\end{array}$ & $\begin{array}{c}\mathrm{C} \\
7,5 \text { à } 10 \text { semaines } \\
(17,5 j)\end{array}$ & $\begin{array}{c}\mathrm{D} \\
10 \text { à } 17 \text { semaines } \\
(49 \mathrm{j})\end{array}$ \\
\hline \multirow{3}{*}{ : } & $\begin{array}{c}\frac{\Delta \mathrm{P}}{\Delta t} \\
\frac{1}{\mathrm{P}} \times \frac{\Delta \mathrm{P}}{\Delta t}\end{array}$ & $\begin{array}{l}028 \\
6,48 \times 10^{-2}\end{array}$ & $\begin{array}{l}0,11 \\
1,5^{\prime} \times 10^{-2}\end{array}$ & $\begin{array}{l}0,0^{\prime} \\
0,48 \times 10^{-2}\end{array}$ & $\begin{array}{l}0,01 \\
0,13 \times 10^{-2}\end{array}$ \\
\hline & $\begin{array}{c}\frac{\Delta(\mathrm{ADN})}{\Delta t} \\
\frac{1}{\mathrm{ADN}} \times \frac{\Delta(\mathrm{ADN})}{\Delta t}\end{array}$ & $\begin{array}{l}3,185 \\
6,00 \times 10^{-2}\end{array}$ & $\begin{array}{l}1,42 \\
1,57 \times 10^{-2}\end{array}$ & $\begin{array}{l}1,49 \\
0,48 \times 10^{-2}\end{array}$ & $\begin{array}{l}0,18 \\
0,16 \times 10^{-2}\end{array}$ \\
\hline & $\begin{array}{l}\frac{\Delta p}{\Delta t} \times 10^{3} \\
\frac{1}{p} \times \frac{\Delta p}{\Delta t}\end{array}$ & $\begin{array}{l}0,59 \\
0,73 \times 10^{-2}\end{array}$ & $\begin{array}{l}\not \# 0 \\
\# 0\end{array}$ & $\begin{array}{l}\# 0 \\
\# 0\end{array}$ & $\begin{array}{l}\# 0 \\
\# 0\end{array}$ \\
\hline \multirow{3}{*}{$\stackrel{\mathscr{9}}{0}$} & $\begin{array}{c}\frac{\Delta \mathrm{P}}{\Delta t} \\
\frac{1}{\mathrm{P}} \times \frac{\Delta \mathrm{P}}{\Delta t}\end{array}$ & $7,28 \times 10^{-2}$ & $\begin{array}{l}0,21 \\
2,79 \times 10^{-2}\end{array}$ & $\begin{array}{l}0,20 \\
1,83 \times 10^{-2}\end{array}$ & $\begin{array}{l}0,05 \\
0,37 \times 10^{-2}\end{array}$ \\
\hline & $\begin{array}{c}\frac{\Delta(\mathrm{ADN})}{\Delta t} \\
\frac{1}{\mathrm{ADN}} \times \frac{\Delta(\mathrm{ADN})}{\Delta t}\end{array}$ & $6,89 \times 10^{-2}$ & $\begin{array}{l}1,20 \\
2,58 \times 10^{-2}\end{array}$ & $\begin{array}{l}0,89 \\
1,37 \times 10^{-2}\end{array}$ & $\begin{array}{l}0,20 \\
0,24 \times 10^{-2}\end{array}$ \\
\hline & $\begin{array}{l}\frac{\Delta p}{\Delta t} \times 10^{3} \\
\frac{1}{p} \times \frac{\Delta p}{\Delta t}\end{array}$ & $0,46 \times 10^{-2}$ & $\begin{array}{l}0,40 \\
0,25 \times 10^{-2}\end{array}$ & $\begin{array}{l}0,77 \\
0,47 \times 10^{-2}\end{array}$ & $\begin{array}{l}0,22 \\
0,13 \times 10^{-2}\end{array}$ \\
\hline \multirow{3}{*}{ 总 } & $\begin{array}{c}\frac{\Delta \mathrm{P}}{\Delta t} \\
\frac{1}{\mathrm{P}} \times \frac{\Delta \mathrm{P}}{\Delta t}\end{array}$ & $\begin{array}{l}4,2 \\
6,53 \times 10^{-2}\end{array}$ & $\begin{array}{l}4,6 \\
3,43 \times 10^{-2}\end{array}$ & $\begin{array}{l}4,8 \\
2,21 \times 10^{-2}\end{array}$ & $\begin{array}{l}2,1 \\
0,67 \times 10^{-2}\end{array}$ \\
\hline & $\begin{array}{c}\frac{\Delta(\mathrm{ADN})}{\Delta t} \\
\frac{1}{\mathrm{ADN}} \times \frac{\Delta(\mathrm{ADN})}{\Delta t}\end{array}$ & $4,83 \times 10^{-2}$ & $\begin{array}{l}11,77 \\
1,8+\times 10^{-2}\end{array}$ & $\begin{array}{l}7,60 \\
0,9^{\prime} \times 10^{-2}\end{array}$ & $\begin{array}{l}2,83 \\
0,30 \times 10^{-2}\end{array}$ \\
\hline & $\begin{array}{l}\frac{\Delta p}{\Delta t} \times 10^{3} \\
\frac{1}{p} \times \frac{\Delta p}{\Delta t}\end{array}$ & $2,0^{\prime} \times 10^{-2}$ & $1,67 \times 10^{-2}$ & $1,31 \times 10^{-2}$ & $\begin{array}{l}1,25 \\
0,38 \times 10^{-2}\end{array}$ \\
\hline
\end{tabular}


Les calculs sont rassemblés dans le tableau 9 .

Il apparaît, d'après ces calculs, que :

$\frac{\mathrm{I}}{\mathrm{ADN}} \frac{\Delta(\mathrm{ADN})}{\Delta t}+\frac{\mathrm{I}}{\bar{p}} \frac{\Delta p}{\Delta t}$ est généralement différent de $\frac{\mathrm{I}}{\mathrm{P}} \frac{\Delta \mathrm{P}}{\Delta t}$ de o à 5 p. Ioo près.

Ceci est dî̀ à l'approximation qui a été faite en prenant des moyennes arithmétiques pour le calcul de $\mathrm{P}, \mathrm{ADN}$ et $p$, c'est-à-dire en confondant les arcs et leur corde.

Les importances relatives de la division et du grandissement cellulaires (exprimées en p. roo de leur somme) sur la croissance de l'intestin grêle, du foie et de la carcasse sont indiquées dans le tableau io.

\section{Résultats}

\section{a) Intestin grêle}

La croissance pondérale de l'organe est rapide de 3 à 7,5 semaines, lente ensuite, quoique continue. L'intestin grêle croît en poids aussi vite que l'ensemble du corps de 3 à 5 semaines $\left(\frac{\text { poids intestin grêle }}{\text { poids vif }} \times\right.$ IOo $\left.=6\right)$ plus lentement ensuite. VoDovar (I964) a montré que dans le cas du porc, le poids de l'intestin grêle vide en p. Ioo du poids vif était croissant de la naissance au sevrage (de 0,89 à I, I5 p. roo) et devenait constant peu après le sevrage $(\mathrm{r}, 23 \mathrm{p}$. Ioo).

TABLEAU IO

Intervention relative de la multiplication cellulaire et du grandissement cellulaire dans la croissance de l'intestin grêle, du foie et de la carcasse du rat blanc

\begin{tabular}{|c|c|c|c|c|c|}
\hline & \multirow[t]{2}{*}{ Périodes } & $\begin{array}{c}\mathrm{A} \\
3 \text { à } 5 \text { semaines } \\
(14 \mathrm{j})\end{array}$ & $\begin{array}{c}\mathrm{B} \\
5 \text { à } 7,5 \text { semaines } \\
(17,5 \mathrm{j})\end{array}$ & 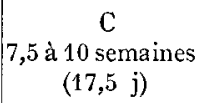 & $\begin{array}{c} \\
10 \text { à } 17 \text { semaines } \\
\\
(49 j)\end{array}$ \\
\hline & & p. 100 & p. 100 & p. 100 & p. 100 \\
\hline \multirow{2}{*}{. } & Multiplication cellulaire & 89 & 100 & 100 & 100 \\
\hline & Grandissement cellulaire & 11 & 0 & 0 & 0 \\
\hline \multirow{2}{*}{ 芫 } & Multiplication cellulaire & 94 & 91 & 74,5 & 65 \\
\hline & Grandissement cellulaire & 6 & 9 & 25,5 & 35 \\
\hline \multirow{2}{*}{ 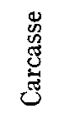 } & Multiplication cellulaire & 70 & 52 & 42 & 44 \\
\hline & Grandissement cellulaire & 30 & 48 & 58 & 56 \\
\hline
\end{tabular}

On observe donc des différences quant au développement de l'intestin grêle chez deux espèces d'animaux monogastriques, connus pour avoir le même type de besoins alimentaires et qui, en l'occurence, ont été nourris de façon très comparable. 
On peut penser aussi qu'à l'intérieur d'une même espèce les aliments apportés et leur présentation peuvent avoir une influence sur la croissance de l'intestin grêle.

Compte tenu de ces réserves, les résultats exposés peuvent se résumer ainsi:

- dès 5 semaines, la taille des cellules ne change pratiquement plus;

- à partir de 7,5 semaines, l'intestin grêle de rats recevant la ration décrite plus haut, a acquis son " capital " d'ARN et la plus grande partie de son " capital " d'ADN ; les variations des teneurs de cellules en nucléotides acido-solubles sont peu accusées.

En conséquence, il semble que 1'intestin grêle du rat, ait atteint la structure adulte à 7,5 semaines, bien que sa croissance se poursuive lentement bien après cet âge.

D'après nos résultats (tabl. 9 et Io), pendant la période $A$, la multiplication cellulaire intervient pour go $\mathrm{p}$. Ioo pour la croissance de l'organe ; la part revenant au grandissement cellulaire, quoique faible, n'est pas négligeable. Au cours des périodes suivantes, il apparaît que la croissance de l'intestin grêle est due à la seule multiplication cellulaire.

D'une étude sur l'ensemble du tube digestif du rat de race Sherman, EnEsco et LEBLOND (I962) concluaient : " Le gain de poids du tube digestif semblerait être principalement, sinon exclusivement, le résultat de l'augmentation du nombre de cellules avec l'âge. "Ce qui est confirmé par nos propres résultats.

\section{b) Foie}

En calculant nos résultats à 1'aide de la relation $n^{0} 4$ (tabl. 9-Io), il ressort que pendant toute la période étudiée, la croissance du foie est principalement due à la multiplication cellulaire jusqu'à 7,5 semaines. Au-delà de cet âge, le grandissement cellulaire devient de plus en plus important, mais dans le foie une proportion importante de noyaux devenant polyploïdes, le contenu moyen d'ADN par noyau augmente avec 1'âge ('Thomson et al., I953; FukUda et Sibatanr, I953; Enesco, I957-I962); la mesure de l'ADN au cours de la croissance ne permet donc plus d'apprécier exactement l'augmentation du nombre de noyaux.

Si l'on calcule la moyenne des résultats obtenus par 'THомson d'une part et ENESCO d'autre part, on peut adopter 7,5 picogrammes comme quantité d'ADN contenue dans un noyau de foie de rats âgés de 3 semaines; pour des rats âgés de 7 semaines et plus, ces auteurs estiment 1'un et l'autre que cette quantité s'élève à 9,5 picogrammes. Pour les âges intermédiaires, THouson ne fournit pas de résultats et ENEsco trouve $9,3 \mu \mathrm{g}$ dès 5 semaines.

En recalculant les données du tableau ro pour le foie à partir des données d'ENEsco, on obtient les résultats suivants :

\begin{tabular}{|c|c|c|c|c|}
\hline & $\begin{array}{c}\text { A } \\
\text { p. } 100\end{array}$ & $\begin{array}{c}\text { B } \\
\text { p. } 100\end{array}$ & $\begin{array}{c}\mathrm{C} \\
\text { P. } 100\end{array}$ & $\begin{array}{c}\mathrm{D} \\
\text { p. } 100\end{array}$ \\
\hline Multiplication cellulaire ... & 76 & 87 & 74,5 & 65 \\
\hline Grandissement cellulaire. & 21 & 13 & 25.5 & 35 \\
\hline
\end{tabular}


Pour les périodes $\mathrm{A}$ et $\mathrm{B}$, les résultats calculés d'après ExEsco sont difficiles à interpréter : la division cellulaire interviendrait pour $7^{6} \mathrm{p}$. roo seulement dans la croissance du foie de 3 à 5 semaines et pour $87 \mathrm{p}$. Ioo entre 5 et 7,5 semaines. Ceci conduit à penser que la quantité d'ADN dans un noyau de foie d'un rat de 5 semaines est inférieure à 9,3 picogrammes.

Cependant, aucune vérification n'ayant été effectuée ni entreprise à ce sujet, ces dernières considérations relèvent du seul domaine de l'hypothèse.

Quoiqu'il en soit, il s'avère que de 3 à I7 semaines, la croissance du foie est due principalement à la multiplication cellulaire.

On peut résumer ainsi l'ensemble des résultats :

- à partir de ro semaines :

la croissance pondérale du foie devient lente;

les synthèses d'ADN et d'ARN deviennent moins importantes;

les teneurs par noyau en nucléotides acido-solubles tendent en moyenne, à diminuer ;

d'après la plupart des auteurs la quantité moyenne d'ADN par noyau devient stable.

Toutes ces remarques permettent de penser que le foie du rat atteint ce que nous appellerons un "équilibre fonctionnel " chez l'animal de Io semaines.

Néanmoins, la croissance du foie se poursuit pendant plusieurs semaines encore au-delà de cet âge.

\section{c) Carcasse}

La croissance se poursuit à un niveau assez élevé jusqu'à I7 semaines. De ro à I7 semaines, le nombre des cellules augmente encore d'une façon appréciable; celles-ci grandissent et augmentent leur teneur en protéines.

Pour ce qui est de la composition globale de la carcasse nos résultats diffèrent sensiblement de ceux qui ont été obtenus par RÉRAT et al. (rg64) sur rat entier : ces auteurs n'ont pas constaté une augmentation soudaine de la teneur en lipides entre $200 \mathrm{~g}$ et $300 \mathrm{~g}$ (et la chute de la teneur en eau qui lui correspond). Il est vrai que les régimes alimentaires utilisés, et vraisemblablement aussi la vitesse de croissance des animaux sont différents. Ceci explique peut-être aussi le fait que nous n'ayons pas constaté une diminution de la teneur en minéraux des tissus, mais au contraire, une augmentation, au moins chez des animaux dont le poids augmente de 39 à $282 \mathrm{~g}$. Nos résultats exprimés en gramme p. Ioo de la matière sèche sont exacts $\grave{a} \pm 0,5 \mathrm{~g}$ pour la mesure de l'eau, à $\pm 0,2 \mathrm{~g}$ pour les protéines $(\mathrm{N} \times 6,25)$, à $\pm 0,2 \mathrm{~g}$ pour les cendres. Ceci en raison de la difficulté qu'il y a de réaliser un échantillonnage parfait sur un hachis apparemment homogène mais en réalité assez hétérogène.

Les données calculées à l'aide de l'équation no 4 (tabl. 9 et ro ; fig. 5) montrent que de 3 à 7 semaines, la multiplication cellulaire est le facteur principal de la croissance. $A_{7}$ semaines (fig. 5 : intersections des courbes représentatives des variations de $\frac{\mathrm{I}}{p} \frac{\Delta p}{\Delta t}$ et $\frac{\mathrm{I}}{\mathrm{ADN}} \frac{\Delta(\mathrm{ADN})}{\Delta t}$ en fonction du temps), le grandissement et la multiplication 
cellulaires ont un rôle équivalent. Au-delà de 7 semaines, le grandissement cellulaire l'emporte $\left(5^{8-56} \mathrm{p}\right.$. Ioo).

Un fait remarquable est à noter : au cours des périodes $\mathrm{A}, \mathrm{B}$ et $\mathrm{C}$, l'intervention relative du grandissement cellulaire dans la croissance devient de plus en plus importante. On pourrait être porté à croire que cette tendance ne ferait que s'accentuer au-delà de ro semaines, alors que l'animal pèse déjà près de $300 \mathrm{~g}$. Or, il n'en est rien : l'influence relative du grandissement cellulaire demeure stable au cours des périodes $\mathrm{C}$ et $\mathrm{D}\left(5^{8-56} \mathrm{p}\right.$. IOo).

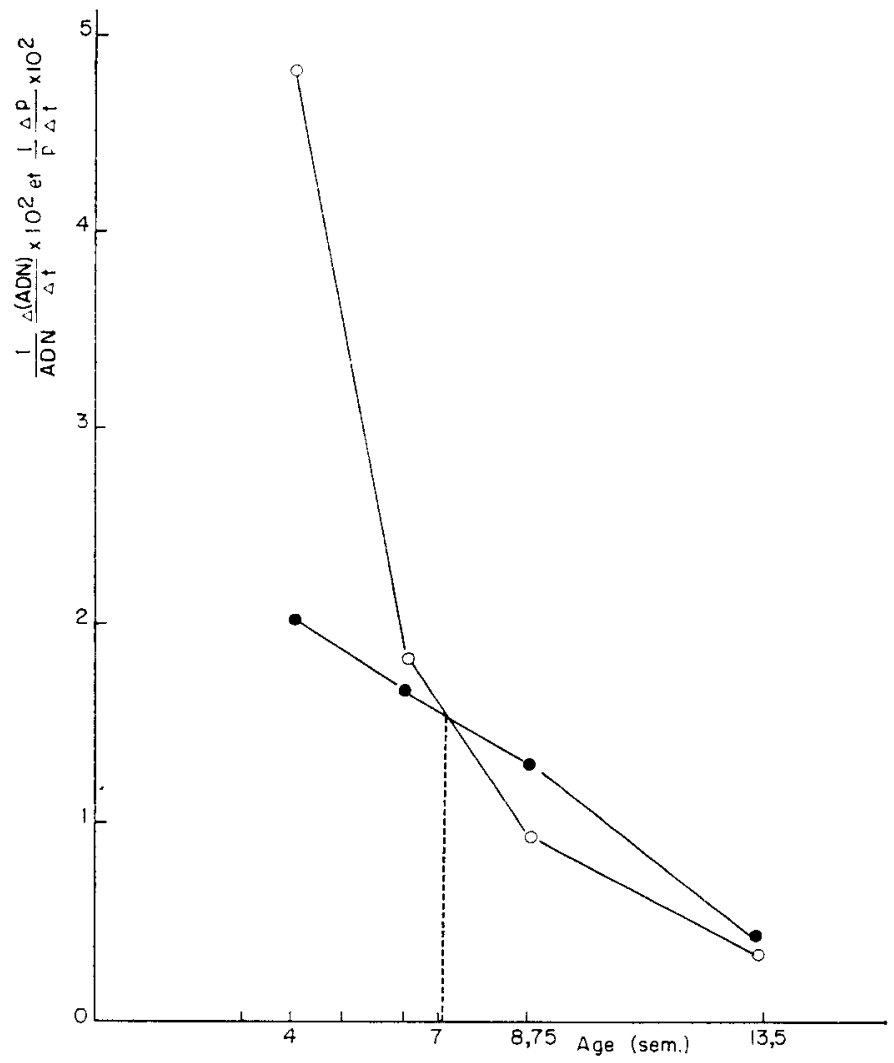

FrG. 5. Carcasse. Évolution en fonction de l'âge, des variations relatives quotidiennes de la multiplication el du grandissement cellulaires

I1 apparaît donc que la multiplication cellulaire reste un facteur important de la croissance de l'organisme longtemps après la puberté.

Une mesure de la quantité moyenne d'ADN par noyau dans les tissus les plus importants constituant la carcasse, nous permettrait d'améliorer l'interprétation de nos résultats. 
SUMMARY

\author{
BIOCHEMICAL STUDY OF GROWTH OF THE SMALL INTESTINE, \\ THE LIVER AND THE CARCASS OF THE RAT : \\ RESPECTIVE ROLES OF PROLIFERATION AND GROWTH IN SIZE OF THE CELLS
}

Investigations were made by biochemical tests which allow the study of changes in phenomena related to the growth of tissues and organs in animals. The investigations were based on the estimation of :

I. Variation in the deoxyribonucleic acid (DNA) content, the amount of which is proportional to the number of nuclei. If the weight of an organ or tissue is divided by the DNA which it contains, an average value is obtained proportional to the amount of living matter associated with each nucleus. By convention, the total of a nucleus and the amount of living matter associated with it is called the " cell ". This convention being accepted, the relation fresh weight/DNA is proportional to the weight of the "cells ", which varies with the "size of the cells".

2. Changes in some aspects of cellular activity measured by contents of ribonucleic acid (RNA) and acid-soluble nucleotides.

Also, a mathematical relationship was established which allowed the estimation of the relative influence of increase in number and of average size of cells on growth.

The method was applied to the small intestine, the liver and the "carcass ", (the whole body less the liver and small and large intestines) of groups of rats aged 3, 5, 7.5, Io and I 7 weeks. The animals were fed to appetite on a semi-synthetic diet with 16 per cent protein which assured satisfactory growth.

It was shown that:

In the small intestine : at 5 weeks of age the size of the cells no longer varied and the amounts of RNA and nucleotides per cell reached a maximum. From 7.5 weeks the weight of the organ and the number of cells increased only very slowly (tables 3 and 4 ). The increase in weight of the organ was due mainly to an increase in the number of cells up to 5 weeks, and entirely to that cause thereafter (tables 9 and 10 ).

In the liver : the weight was related to the weight of the animal up to ro weeks. Later

(a) the weight of the liver and the number of cells which it contained increased less quickly, and

(b) on average the acid-soluble nucleotide content of the cells tended to diminish. The amount of RNA per cell reached a maximum at 7.5 weeks (tables 5 and 6 ). During the whole period studied the growth of the organ was due principally to the proliferation of cells (tables 9 and 10 ).

In the carcass : growth was rapid up to Io weeks, and then slow. A gross analysis showed that the proportion of protein $(\mathrm{N} \times 6.25)$ increased from 3 to 17 weeks, and the same was true for lipids of which the proportion tended to increase steeply after 7.5 weeks (table 7 ).

Increase in the number of cells was the principal cause of growth up to 7 weeks, and thereafter it was increase in the size of the cells (tables 9 and to ; fig. 5).

RNA content of cells was at a maximum when the animals were 5 weeks old (table 8 ).

\title{
RÉFÉRENCES BIBLIOGRAPHIQUES
}

Allfrey V. C., Daly M. M., Mirsky A. E., I954. Synthesis of Protein in the Pancreas. II. The role of ribo:ucleoprotein in protein synthesis. J. gen. Physiol., 37, I 57 -1 75 .

Boivin A., Vendrely R., Vendrely C., 1948. L'acide désoxyribonucléique du noyau cellulaire dépositaire des caractères héréditaires; arguments d'ordre analytique. $C . R$. Acad. Sci. Fr., 226, I061-2,

Brachet J., 1950. Chemical Embryology (New York, Interscience publishers, Inc).

Brachet J., I954. Effects of ribonuclease on the metabolism of Living Root-Tip cells. Nature, 174, $876-877$.

Brachet J., I955. Action of ribonuclease and ribonucleic acid an amoebae. Nalure, 175, $85 \mathrm{I}-853$.

Brody S., 1945. Bioenergetics ant Gronth. New York : Reinhold Publ. Corp.

Burch H. B., Lowry O. H., VoN DIPPE P., 1964. Pyridine nucleotides in developing rat liver. J. Biol. Chem., 239, 1898-1899. 
Burch H. B., Lowry O. H., VoN Dippe P., 1963. The stability of triphosphopyridine nucleotide and its reduced form in rat liver. J. Biol. Chem., 238, $2838-2842$.

Caiger P., Morton R. K., I962. A comparative study of nicotinamide nucleotide coenzymes during growth of the sheep and rat. Biochem. J., 85, 35I-359.

CARRIEtre R., I960. The endocrine control of polyploïd cell formation in the rat liver. Anat. Rec., 136, I75.

-Caspersson T., i95o. Cell Growth and cell function. NewYork, Norton and Co.

ChargafF E., Lipshitz R., 1953. Composition of mammalian desoxyribonucleic acids. J. amer. Chem. Soc., 75, 3658-3661.

ConN W. E., I950. The anion-exchange separation of nucleotides. J. amer. Chem. Soc., 72, 147 I-1478.

CoHN W. E., I955. The separation of nucleic acids and derivatives by chromatography on ion exchange columns, in " the nucleic acids" Vol.1, ed. E. Chargaff et J. N. Davidson, 2 I I-2 I4. New York, Academic Press inc.

Colowick S. P., Kaplan N. O. (Ed) 1957. Methods in Enzymology, Vol. IlI, Section V.

Davioson J. N., Leshie I., I950 a. Nucleic acids in relation to tissue growth. Exp. Cell. Res., 1, I 27 -I 34.

Davidson J. N., Lestie I., I950 $b$. Nucleic acids in relation to tissue growth. Cancer. Res., 10, $587-594$.

Edmonds M. E., LE PAGE G. A., I953. In vivo studies an acido-soluble precursors of nucleic acids purines. Fed. Proc., 12, I99.

EnEsco M., Leblond C. P., I962. Increase in cell number as a factor in the growth of the organs and tissues of the young male rat. J. Embryol. Exp. Morph., 10, Part. 4, 530-532.

Fukuda M., Sibatani A., 1953. Biochemical studies on the number and the composition of liver cells in postnatal growth of the rat. J. Biochem. Tokyo, 40, 95-1 Io.

Fuduka M., Sibatani A., I953. Relation between the body weight and the average DNA content of liver nuclei in postnatal growth of the rat. Exp. Cell. Res., 4, 236-238.

Henry Y., RÉRAT A., I 963 . Étude de l'ingestion spontanée d'éléments énergétiques et de protéines chez le rat en croissance par la méthode du libre choix. Ann. Biol. anim. Bioch. Biophys., 3, ro3-I 7.

Hurlbert R. B., Schmitz H., Brumm A. F., Potter V. R., i954. Nucleotide Metabolism. IT. Chromatographie separation of acid-soluble nucleotides. J. Biol. Chem., 209, 23-39.

Hurlbert R. B., Potter V. R., x952. A survey of the metabolism of orotic acid in the rat. J. Biol. Chem., 195, $257^{-270}$.

Levene P. A., Bass L. W., I931. Nucleic acids (Chemical catalog company, New York).

Mirsky A. E., Ris H., I95I. The desoxyribonucleic acid content of animal cells and its evolutionary significance. J. Gen. Physiol., 34, 45I-462.

NeEdham J., I933. On the dissociability of the fundamental processes in antogenese. Biol. Rev., 8, I80223.

Rérat A., Février C., Henry Y., Lougnon J., ig64. Évolution de la composition corporelle chez le rat blanc en croissance. Ann. Biol. anim. Bioch. Biophys., 4, 35-47.

Schmidt G., Tannhauser S. J., 1945. A method for the determination of desoxyribonucleic acid, ribonucleic acid, and phosphoproteins in animal tissues. J. Biol. Chem., 161, 83-89.

SwifT H. H., I953. Quantitative aspects of nuclear nucleoproteins. Intern. Rev. Cytol., 2, I-69.

Thomson R. Y., Neagy F. C., Hutchinson W. C., Davidson J. N., 1953. DNA content of the rat, cell nucleus and its use in expressing the results of tissue analysis; with particular reference to the composition of liver tissue. Biochem. J., 53, 460-474.

Vodovar N., Flanzy J., Françors A. C., 1964. Intestin grêle du porc. I. Dimensions en fonction de l'âge et du poids, étude de la jonction du canal cholédoque et du canal pancréatique à celui-ci. Ann. Biol. anim. Bioch. Biophys., 4, 27-34. 